\title{
Impact of Satellite Practices on Academic Ophthalmology Departments
}

\author{
Irene C. Kuo, MD ${ }^{1}$ Scott M. Wright, MD² \\ ${ }^{1}$ Department of Ophthalmology, Wilmer Eye Institute, Baltimore, \\ Maryland \\ 2 Department of Medicine, Johns Hopkins University School of \\ Medicine, Baltimore, Maryland
}

\begin{abstract}
Address for correspondence Irene C. Kuo, MD, Department of Ophthalmology, Wilmer Eye Institute, Johns Hopkins University School of Medicine, 4924 Campbell Blvd. \#100, Baltimore, MD 21236 (e-mail: ickuo@jhmi.edu).
\end{abstract}

Journal of Academic Ophthalmology 2017;9:e7-e12.

\begin{abstract}
Keywords

- satellite practices

- satellite clinics

- academic medical centers

- academic medicine

- community practices

- ophthalmology

- academic ophthalmology

- multi-office locations

Background A recent small study described how "satellite" clinics (off-site and strategically situated) associated with six academic ophthalmology departments provided expansion opportunities, and also created unique challenges.

Objectives The aim of this study was to gather a wider viewpoint by surveying chairpersons about their opinions of satellite practices, and how these relate to their departmental mission.

Research Design Online survey.

Subjects Chairperson members of the Association of University Professors of Ophthalmology.

Results More than $60 \%$ of respondents had satellite practices affiliated with their departments. Most departments had two to five satellite practices; $33 \%$ had satellites that were located further than 50 miles away from the main hospital. On average, satellites accounted for 25 to $30 \%$ of total patient visits for the department. Departments whose satellites accounted for $50 \%$ or more of total patient visits to the department were those with the largest clinical volumes $(>100,000$ annual patient visits). Comprehensive ophthalmology was the most common service offered at satellites. All Chairs believed satellite practices had at least maintained, if not improved, their departments' reputation. Seventy percent were concerned about perceived competition with referring community doctors. Research endeavors and trainee education were not considered to be priorities of satellite practices.

Conclusion Overall, chairpersons in the United States believed that satellite practices had strengthened their departments. The geographical expansion of departments, particularly with comprehensive ophthalmology (inclusive of optometric services), has implications for relations with the referral base in the surrounding communities. Thoughtful management of these practices, with attention paid to both meeting financial goals as well as fulfilling the academic mission, is necessary to ensure that the advantages outweigh the drawbacks.
\end{abstract}

In the past 20 years, many academic ophthalmology departments have been expanding by opening satellite offices, located at variable distances from the departmental hub. Many satellite practices are situated in the suburbs, ${ }^{1}$ in contrast to the more central or urban location of most received

September 15, 2016 accepted after revision March 27, 2017
DOI https://doi.org/

10.1055/s-0037-1602768. ISSN 2475-4757. academic medical centers. The published literature on community or satellite practices in academic medicine is scant and most commonly describes affiliations with community hospitals and private practices. ${ }^{2-6}$ A recent small study of satellite practices affiliated with six large academic

Copyright $\odot 2017$ by Thieme Medical Publishers, Inc., 333 Seventh Avenue, New York, NY 10001, USA.

License terms

(c) $(1) \$$ 
ophthalmology departments explored the evolution of their satellite practices and provided a preliminary examination of successes and challenges. ${ }^{1}$ The consensus of leaders of these six programs was that satellites expanded the geographical reach of their departments and benefited their departments financially, in part because of a more favorable payor mix. Other reasons for enhanced profitability at these remote practices were noted to be the increased efficiency, as well as the freedom to promote higher revenue subspecialties at these sites. Changes in the health care system, such as the Affordable Care Act (http://www.hhs.gov/healthcare/ rights/), necessitate amendments to the structure and delivery of care at academic medical centers, ${ }^{7,8}$ whereby the establishment of satellite practices can be advantageous.

Opening a satellite practice is not without risk. Beyond expending effort to maintain the department's respected academic "brand," another consideration is how best to support the faculty practicing at satellites, particularly if these faculty are held to the same academic standards-to contribute substantively to academia's tripartite mission. ${ }^{9,10}$ To that end, faculty at satellites need opportunities and support to advance toward promotion, ${ }^{11}$ and they must be thoroughly integrated into the departmental culture so that they remain engaged and feel valued. ${ }^{11,12}$

To further investigate the impact of satellite practices on academic ophthalmology departments, this study collected the perspectives of departmental leaders, the Chairs, about their satellite offices.

\section{Methods}

\section{Study Design and Sample}

This study was conducted using a cross-sectional survey sent electronically from February through mid-May 2015 to ophthalmology department chairpersons who were members of the Association of University Professors of Ophthalmology (AUPO); select questions are shown in -Table $\mathbf{1}$. Because of the association's policies, its leadership insisted on sending the survey link to all Chairs using a method that preserved confidentiality and prevented the authors from contacting individual Chairs. While this policy was believed to encourage truthful responses, it also precluded us from encouraging nonrespondents to complete the survey. Over a 2-month period, reminder invitations were sent four times by the AUPO manager per our request.

\section{Survey Development, Composition, and Analysis}

We assembled a team to develop a survey instrument that would measure chairpersons' experiences with and perceptions of satellite practices affiliated with their departments of ophthalmology. The survey development team had both expertise in survey design and years of experience in satellite practices. The survey was also informed by our previous research ${ }^{1}$ and a careful review of the literature.

For clarification, satellite practices were defined at the beginning of the survey. It was explained that ophthalmology clinics in Veteran Administration and county hospitals were not considered satellite offices.

The survey included questions about the departments, including annual number of patient visits, number of satellites, ranks of faculty members at satellites, whether trainee education occurred at satellites, as well as the proportion of total visits and revenues that the satellites represented. The instrument also collected information about the Chairs themselves, including age, details of their clinical practice, and grant support. Given the paucity of female Chairs, gender was not asked so as to preserve anonymity. Response options included yes/no, multiple-choice selections, Likert scales,

Table 1 Select questions from instrument used to survey the ophthalmology department Chairs

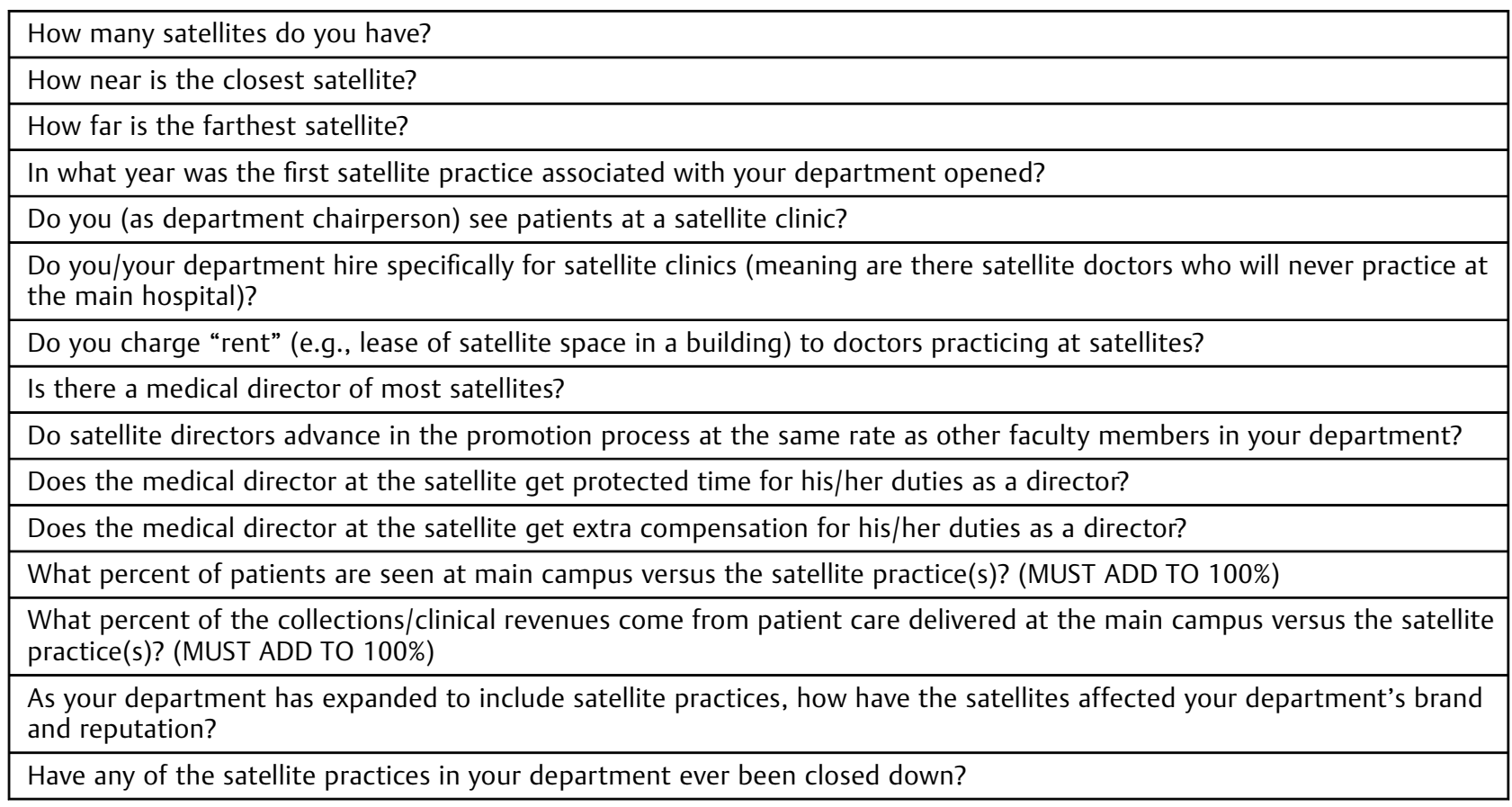


Table 2 Characteristics of responding 51 Chairs and their respective ophthalmology departments

\begin{tabular}{|c|c|}
\hline Chairpersons & \\
\hline $\begin{array}{l}\text { Mean age in years } \\
\text { (standard deviation) }\end{array}$ & $57(5)$ \\
\hline $\begin{array}{l}\text { Mean percent time } \\
\text { devoted to clinical care }\end{array}$ & $43 \%$ \\
\hline $\begin{array}{l}\text { Mean percent time } \\
\text { devoted to research }\end{array}$ & $14 \%$ \\
\hline $\begin{array}{l}\text { Has extramural support } \\
\text { for research }\end{array}$ & $65 \%$ \\
\hline $\begin{array}{l}\text { Cares for patients at } \\
\text { satellite practice }\end{array}$ & $50 \%$ \\
\hline Departments & $\begin{array}{l}\text { Number (\%) of Chairs with } \\
\text { affirmative response } \\
\text { (where applicable) }\end{array}$ \\
\hline \multicolumn{2}{|l|}{ Total outpatient visits/year } \\
\hline Range & $3,000-250,000$ \\
\hline Median & 65,000 \\
\hline $\begin{array}{l}\text { Mean } \pm \text { standard } \\
\text { deviation }\end{array}$ & $77,000 \pm 55,000$ \\
\hline $\begin{array}{l}\text { Departments with } \\
\text { affiliated satellite } \\
\text { practice, } n(\%)\end{array}$ & $30(63)$ \\
\hline \multicolumn{2}{|l|}{ Number of satellite practices } \\
\hline 1 satellite & $3(10 \%)$ \\
\hline 2-5 satellites & $18(58 \%)$ \\
\hline $6-10$ satellites & $5(16 \%)$ \\
\hline$>10$ satellites & $5(16 \%)$ \\
\hline \multicolumn{2}{|l|}{ Location of satellite practices } \\
\hline $\begin{array}{l}\text { Closest satellite }<10 \text { miles } \\
\text { from the main campus }\end{array}$ & $21(71 \%)$ \\
\hline $\begin{array}{l}\text { Farthest satellite }>50 \\
\text { miles from the main } \\
\text { campus }\end{array}$ & $10(33 \%)$ \\
\hline \multicolumn{2}{|l|}{ Satellite experience and longevity } \\
\hline $\begin{array}{l}\text { Oldest satellites } \\
\text { established }<5 \text { years old }\end{array}$ & $3(10 \%)$ \\
\hline $\begin{array}{l}\text { Oldest satellites }>15 \text { years } \\
\text { old }\end{array}$ & $20(66 \%)$ \\
\hline \multicolumn{2}{|l|}{ Satellite workforce } \\
\hline $\begin{array}{l}\text { Comprehensive } \\
\text { ophthalmologists } \\
\text { working at satellites }\end{array}$ & $30(97 \%)$ \\
\hline $\begin{array}{l}\text { Optometrists working } \\
\text { at satellites }\end{array}$ & $24(93 \%)$ \\
\hline $\begin{array}{l}\text { Junior faculty (assistant } \\
\text { professor or equivalent) }\end{array}$ & $26(87 \%)$ \\
\hline $\begin{array}{l}\text { Mid-level faculty } \\
\text { (associate professor } \\
\text { or equivalent) }\end{array}$ & $26(87 \%)$ \\
\hline $\begin{array}{l}\text { Senior faculty (full } \\
\text { professor or equivalent) }\end{array}$ & $26(87 \%)$ \\
\hline
\end{tabular}

(Continued)
Table 2 (Continued)

\begin{tabular}{|l|l|}
\hline \multicolumn{2}{|l|}{ Satellite workforce } \\
\hline $\begin{array}{l}\text { Satellite faculty } \\
\text { who are }>50 \% \text { full-time } \\
\text { equivalent clinical }\end{array}$ & $28(93 \%)$ \\
\hline $\begin{array}{l}\text { Satellite faculty } \\
\text { who are }>50 \% \\
\text { full-time equivalent } \\
\text { research }\end{array}$ & $6(20 \%)$ \\
\hline Subspecialties at satellites (\%) \\
\hline $\begin{array}{l}\text { Comprehensive } \\
\text { ophthalmology }\end{array}$ & $27(97 \%)$ \\
\hline Retina & $24(74 \%)$ \\
\hline Pediatrics & $21(68 \%)$ \\
\hline Cornea & $21(68 \%)$ \\
\hline Glaucoma & $19(61 \%)$ \\
\hline Oculoplastics & $15(48 \%)$ \\
\hline Laser refractive surgery
\end{tabular}

and free text boxes that allowed for written responses. Pilot testing with senior, experienced division chiefs was conducted to assess clarity and lack of ambiguity in the questions.

The Johns Hopkins Medicine Institutional Review Board X determined this work qualified as exempt research under Title 45, Public Welfare Department of Health and Human Services Code of Federal Regulations Protection of Human Subjects 46.101(b).

\section{Data Analysis}

Descriptive statistics of the data abstracted was performed, and data are presented as medians, means with standard deviations, and proportions.

\section{Results}

The survey was sent to 110 chairperson members of the AUPO in the United States. Fifty-one (46\%) Chairs responded. Their mean age was 57 years (-Table 2). On average, the Chairs devoted $43 \%$ of their time to direct patient care, and $14 \%$ to research. Sixty-five percent $(n=33)$ had external funding to support their research efforts. Approximately half of responding Chairs (53\%) were working at public institutions.

The Chairs who responded lead departments of variable clinical productivity, ranging from 3,000 patient visits/year to 250,000 patient visits/year; the median was 65,000 visits/year, and the mean \pm standard deviation was $77,000 \pm 55,000$ visits/year. More than $60 \%$ of respondents $(n=32)$ confirmed that their department had at least one satellite office.

The advantages and benefits that Chairs most commonly attributed to having satellites were "expanding the department's geographic reach" and "increasing patient volumes" (-Table 3). Of the 16 respondents whose departments had no satellites, economic reasons ("does not make sense 
Table 3 Ophthalmology department Chairs' impressions about the perceived challenges and benefits associated with running their satellite practices

\begin{tabular}{|l|l|}
\hline \multicolumn{2}{|l|}{ Challenges, $\boldsymbol{n}$ (\%) } \\
\hline $\begin{array}{l}\text { Competition (real or perceived) with } \\
\text { referring doctors in the community }\end{array}$ & $18(69)$ \\
\hline Integration of satellite practices/doctors & $10(38)$ \\
\hline $\begin{array}{l}\text { Maintenance of consistent standards/ } \\
\text { operating procedures throughout the } \\
\text { department }\end{array}$ & $7(27)$ \\
\hline $\begin{array}{l}\text { Mentorship of physicians at satellite } \\
\text { practices }\end{array}$ & $5(19)$ \\
\hline $\begin{array}{l}\text { Providing resources to support satellite } \\
\text { practices }\end{array}$ & $4(15)$ \\
\hline Brand preservation & $3(12)$ \\
\hline Benefits, $\boldsymbol{n}$ (\%) & $30(97)$ \\
\hline Expand geographic reach of departments & $29(94)$ \\
\hline $\begin{array}{l}\text { Enhance accessibility to referring doctors } \\
\text { in the community }\end{array}$ & $17(55)$ \\
\hline $\begin{array}{l}\text { Help in recruiting patients for studies/ } \\
\text { trials }\end{array}$ & $11(35)$ \\
\hline $\begin{array}{l}\text { Perform procedures/surgeries at sites } \\
\text { with lower costs }\end{array}$ & $10(33)$ \\
\hline $\begin{array}{l}\text { Proximity to sources of grateful patient } \\
\text { philanthropy }\end{array}$ & $\begin{array}{l}\text { Hiring doctors with clinical and/or } \\
\text { research interests that cannot be } \\
\text { accommodated at the main hospital }\end{array}$ \\
\hline
\end{tabular}

financially for us") was cited most frequently, followed by " $n o$ perceived benefit" and "perceived competition with community doctors will decrease referrals to the department." More than half of these respondents $(n=10)$ said they would likely open a satellite practice within the next 5 years.

While $95 \%$ of Chairs "strongly agreed" or "agreed" with the statement "Satellite practices have been a great success," 35\% recounted that their department had closed one or more satellite offices, mostly because they were not financially viable.

\section{Details of the Satellite Practices}

More than half of the departments with satellites reported having two to five such practices (-Table 2). Sixty-six percent of respondents said their oldest satellite had been operating for longer than 15 years.

Comprehensive ophthalmology was the most common service offered at satellites (- Table 2 ); the subspecialty of refractive surgery was offered at just less than $50 \%$ of the satellites.

Trainees (residents or fellows) were sent to satellites in half the departments with satellite practices. In such departments, all Chairs believed that the quality of the teaching and the educational experience were as good as or better than at the main campus. Chairs of departments which elected not to send trainees to satellites cited these top two reasons: "not enough pathology at satellites [for them] to benefit" and "having trainees at satellites would decrease the practice's efficiency."

Eighty-five percent of Chairs asserted that they decide which doctors practice at satellites. Half of the respondents explained that they hire doctors specifically for satellite practices, meaning these doctors have no clinical roles at the main hospital. The doctors working at satellites consisted of a mix of junior, mid-range, and senior faculty (-Table 2). Fewer than half of satellites had a formal "medical director"; few respondents divulged whether directors have protected time for their administrative duties and whether these people receive extra compensation for assuming this role.

\section{Finances}

Satellites accounted for 25 to $30 \%$ of total visits, total new patient visits, and total departmental collections ( - Fig. 1). Satellite visits accounted for less than $50 \%$ of total department visits in all nine departments with 40,000 or fewer visits/year. Five of six (83\%) departments whose satellites accounted for $50 \%$ or more of total visits had more than 100,000 patient visits/year. In these departments with more patient visits, satellites collected a higher proportion of revenues compared with the proportion of visits they represented. In departments with fewer patient visits, satellites collected a lower proportion of revenues relative to the proportion of visits.

Eight of 30 (27\%) departments with satellites charged rent to satellite practices, and 7 (88\%) of these departments also charged rent to physicians practicing on the main campus, with rent at both locations said to be similar.

\section{Experiences Integrating Satellites}

No Chair reported that establishing satellite practices had negatively impacted the departmental "brand" and reputation. To maintain the quality of the brand, the strategies most commonly employed were to "hire doctors for the department, not for the satellite, then have them split time between main campus and satellites" (46\%) and to "mandate that clinicians practicing at the satellites are faculty, rather than clinical associates [or the like]" (38\%). Fifty percent of Chairs said they had clinical time at satellites, which they believed helped in myriad ways.

\section{Discussion}

In this survey, almost all chairpersons of academic ophthalmology programs with satellite practices affirmed that their departments benefited from having satellite offices. They agreed that satellites increased patient volume while maintaining or improving the department's reputation and brand. Many departments currently without satellite practices are in the process of establishing them because they appreciate the added value.

This study expands on our earlier small study that superficially explored aspects of satellite practices affiliated with six large ophthalmology departments. ${ }^{1}$ In the literature, aside from that pilot study, ${ }^{1}$ we found only a few references about 


\section{Total visits to department}

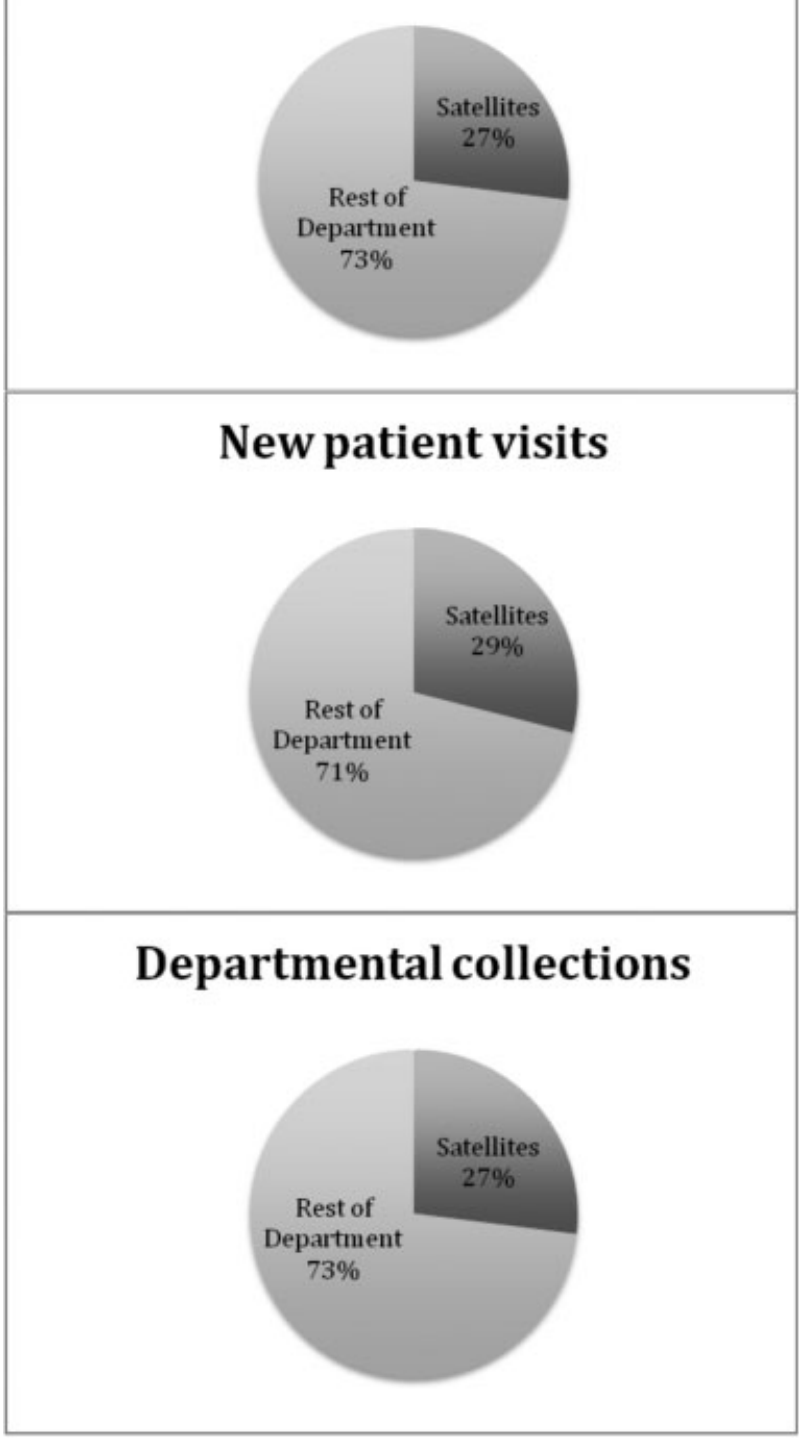

Fig. 1 Breakdown of total visits (top panel), new patient visits (middle panel), and revenues (lowest panel) between the departmental academic hub and their satellite practices averaged for the 30 ophthalmology departments with at least one satellite practice.

"satellite offices/practices/clinics" related to academic medical centers. These included a study describing clinical teaching at a remote satellite ${ }^{13}$; academic surgical practices strengthening their position in the "market" by having "satellite networks"14; an oncology department and architect planning space needs at a "community hospital satellite"15; and a pediatric sickle cell disease group showing that a satellite produced clinical outcomes comparable with those of the university-based clinic while concomitantly alleviating the barriers associated with travel. ${ }^{4}$ Beyond the marked positive impact on finances when an academic pediatric radiology division expanded into the community, ${ }^{6}$ there was also improved referring physician and patient satisfaction. ${ }^{5}$ Nonetheless, the authors of this article ${ }^{5}$ discussed how the benefits of community practice were associated with some decreased efficiency attributable to travel time between satellites and the main campus. They stated this decreased efficiency negatively affected teaching and clinical consultation. ${ }^{5}$

Satellite practices may flourish only after departments reach a critical mass. Size matters not only with regard to the number of physicians but also to having sufficient infrastructure for resources (both human and otherwise) to coordinate health information technology and clinical integration. ${ }^{8}$ The departments with the highest clinical volumes had a longer history of satellites, a larger number of satellites, a higher proportion of their total visits seen at the satellite practices compared with the main campus, and disproportionately higher revenues (relative to visits) from satellite practices. While not shown in detail in "Results" section, more established satellite practices account for a larger percentage of total and new patient visits, thereby creating opportunity for growth and expansion. ${ }^{2}$ One inference is that while departments may need to reach a "critical mass" in order for their satellite practices to flourish, satellites can help departments reach that critical mass. Optometric presence and comprehensive ophthalmologists are now common in departments and satellites, offering "general eye care," which is clearly a departure from the focus of academic departments in the past. Some satellite practices, however, have failed and closed, serving as a reminder of the importance of a detailed market analysis as well as careful selection of people and location to maximize the chance of success. Satellite practices may help departments in the United States face challenging health care reforms in the near future, just as satellites helped with the penetration of health maintenance organizations in the United States two decades ago. ${ }^{14}$

A core mission of academic departments is to train the next generation of physicians and surgeons. Health care reform is anticipated to have an impact on education. ${ }^{16-18}$ Fewer than half of the departments with satellite practices are sending trainees to these clinics, but over time, this ratio may need to change. This adjustment may parallel shifts occurring in internal medicine in the United States with a marked transition from the inpatient setting to outpatient practices as the ideal venue to learn contemporary medicine. ${ }^{19-21}$ Beyond the differences in patient populations and pathology between hospital and satellite practices, learning to work in settings with increased efficiency may better equip graduates for work that awaits them after graduation. Although there might be variability in the educational experiences beyond the academic centers, ${ }^{22}$ educators will need to evaluate the curricular processes and outcomes at these sites. Without a strong focus on research or teaching (both of which may be more challenging for busy clinicians), expansion of satellite practices may pose a challenge to academic integration of satellite doctors.

Several limitations of this study should be considered. First, the opinions of Chairs may be different from some of the other stakeholders involved in satellite practices. Because Chairs ultimately make departmental decisions, their perspectives are important to understand. Second, many Chairs did not share their opinions and complete the survey. It is impossible to know whether the viewpoints of nonresponders are different. 
While the AUPO was supportive and helpful in distributing the survey, their rules related to surveying their membership may have impacted upon our ability to secure a higher response rate and prevented us from knowing which programs responded and which ones did not. While we have no way of knowing for certain, we posit that a high proportion of nonrespondents did not have satellite practices and felt they had little to add. In fact, the AUPO manager communicated to us that a few Chairs asked whether they should complete the survey if their department did not have satellite practices. Nonetheless, our response rate is comparable to that published in the medical literature. ${ }^{23-26}$ Third, the research focuses exclusively on academic departments in the United States and it is not clear whether these findings can be generalized internationally or would be applicable in other health care systems. Finally, we relied on selfreport to collect the information from responding Chairs, the only practical means to learn about attitudes. Because the AUPO's policies guaranteed anonymity, we are hopeful that the informants were candid in their responses.

Given the need for academic medical centers to adapt nimbly to health care reform and changes in reimbursement, the experience of academic ophthalmology departments and their satellite practices is particularly relevant at this time. This study represents an early attempt to characterize the issues associated with satellite practices in a surgical subspecialty. This description of ophthalmology satellite practices may be relevant for other specialties in the United States contemplating building satellite practices. As large academic medical centers form their own accountable care organizations, "satellite networking" with community hospitals and private practices described in studies from a decade or more ago $^{5,6,14}$ may no longer be feasible, and academic departments may need to establish satellite practices with their departmental "brand." Future studies that delve deeply into matters such as the finances and support of the academic mission will answer additional questions about how and when to incorporate satellite practices most successfully into the portfolio of academic surgical departments.

\section{Funding}

Dr. Wright is a Miller-Coulson Family Scholar and he is supported to direct the Miller Coulson Academy of Clinical Excellence through the Johns Hopkins Center for Innovative Medicine.

\section{References}

1 Kuo IC. Satellite clinics in academic ophthalmology programs: an exploratory study of successes and challenges. BMC Ophthalmol 2013;13:79

2 Helzner J. Major eye centers in expansion mode: should independent practices in their orbit be concerned? Ophthalmology Management. February 2011:55-58. Available at: http://www. ophmanagement.com/article.aspx?article $=105236$. Accessed October 21, 2011

3 Bentley JD, Chusid J, D’Antuono GR, Kelly JV, Tower DB. Faculty practice plans: the organization and characteristics of academic medical practice. Acad Med 1991;66(08):433-439
4 Hamm J, Hilliard L, Howard T, Lebensburger J. Maintaining high level of care at satellite sickle cell clinics. J Health Care Poor Underserved 2016;27(01):280-292

5 Ecklund K, Share JC. Extension of academic pediatric radiology to the community setting: experience in two sites. Pediatr Radiol 2000;30(01):3-6

6 Coran AG, Blackman PM, Sikina C, et al. Specialty networking in pediatric surgery: a paradigm for the future of academic surgery. Ann Surg 1999;230(03):331-337, discussion 337-339

7 Stein D, Chen C, Ackerly DC. Disruptive innovation in academic medical centers: balancing accountable and academic care. Acad Med 2015;90(05):594-598

8 Berkowitz SA, Miller ED. Accountable care at academic medical centers-lessons from Johns Hopkins. N Engl J Med 2011;364 (07):e12

9 Barzansky B, Kenagy G. The full-time clinical faculty: what goes around, comes around. Acad Med 2010;85(02):260-265

10 Bucklin BA, Valley M, Welch C, Tran ZV, Lowenstein SR. Predictors of early faculty attrition at one Academic Medical Center. BMC Med Educ 2014;14(01):27

11 Thomas PA, Diener-West M, Canto MI, Martin DR, Post WS, Streiff MB. Results of an academic promotion and career path survey of faculty at the Johns Hopkins University School of Medicine. Acad Med 2004;79(03):258-264

12 Durso SC, Christmas C, Kravet SJ, Parsons G, Wright SM. Implications of academic medicine's failure to recognize clinical excellence. Clin Med Res 2009;7(04):127-133

13 Fox BI, McDonough SL, McConatha BJ, Marlowe KF. Establishing and maintaining a satellite campus connected by synchronous video conferencing. Am J Pharm Educ 2011;75(05):91

14 Flint L, Flint CB. Academic surgical group practices at the dawn of health reform. Ann Surg 1994;220(03):374-378, discussion 378-381

15 Bloom M, Markovitz S, Silverman S, Yost C. Ten trends transforming cancer care and their effects on space planning for academic medical centers. HERD 2015;8(02):85-94

16 DiSesa VJ, Kaiser LR. What's in a name? The necessary transformation of the academic medical center in the era of population health and accountable care. Acad Med 2015;90(07):842-845

17 Kahn MJ, Maurer R, Wartman SA, Sachs BP. A case for change: disruption in academic medicine. Acad Med 2014;89(09): 1216-1219

18 Wartman SA. Toward a virtuous cycle: the changing face of academic health centers. Acad Med 2008;83(09):797-799

19 Huddle TS, Heudebert GR. Internal medicine training in the 21st century. Acad Med 2008;83(10):910-915

20 Arora V, Guardiano S, Donaldson D, Storch I, Hemstreet P. Closing the gap between internal medicine training and practice: Recommendations from recent graduates. Am J Med 2005;118 (06):680-685, discussion 685-687

21 Whitcomb ME, Cohen JJ. The future of primary care medicine. N Engl J Med 2004;351(07):710-712

22 Gruppen LD, Wisdom K, Anderson DS, Woolliscroft JO. Assessing the consistency and educational benefits of students' clinical experiences during an ambulatory care internal medicine rotation. Acad Med 1993;68(09):674-680

23 Mandel HG; The National Caucus of Basic Biomedical Science Chairs. Downsizing of basic science departments in U. S. medical schools: perceptions of their chairs. Acad Med 1997;72(10):894-900

24 Souba W, Notestine M, Way D, Lucey C, Yu L, Sedmak D. Do deans and teaching hospital CEOs agree on what it takes to be a successful clinical department chair? Acad Med 2011;86(08): 974-981

25 Peterson LE, Blackburn B, Phillips RL Jr, Mainous AG III. Family medicine department Chairs' opinions regarding scope of practice. Acad Med 2015;90(12):1691-1697

26 Hemmer PA, Alper EJ, Wong RY. Participation of internal medicine department chairs in the internal medicine clerkship-results of a national survey. Acad Med 2005;80(05):479-483 